\title{
Impact of the consumer cooking practices on acrylamide formation during the preparation of French fries in Spanish households
}

\author{
Marta Mesías, Cristina Delgado-Andrade, Francisca Holgado, Francisco J Morales
}

Instituto de Ciencia y Tecnología de Alimentos y Nutrición (ICTAN-CSIC), Madrid-, Spain

\begin{abstract}
An observational study in 208 volunteers in households from 30 Spanish provinces was conducted from May to June 2017 in order to evaluate the formation of acrylamide during the preparation of French fries from fresh potatoes. Consumer cooking practices and household typology were evaluated with an ad-hoc questionnaire. Potatoes (fresh and fried) and frying oil were collected from the households. A total of $36.1 \%$ of samples contained acrylamide above the benchmark level for French fries $\left(500 \mu \mathrm{gg}^{-1}\right)$. The mean acrylamide content $\left(550 \mu \mathrm{gg}^{-1}\right)$ and P95 $\left(1747 \mu \mathrm{g} \mathrm{kg}{ }^{-1}\right)$ were higher than values reported by EFSA (308 $\mu \mathrm{g}$ $\mathrm{kg}^{-1}$ and $97 \mathrm{I} \mu \mathrm{kg}^{-1}$, respectively). Although the color 'golden' was the criteria to decide the end-point of frying, nearly $40 \%$ of the consumers misclassified it. Acrylamide was significantly correlated with the color parameter $\mathrm{a}^{*}$, even in this random scenario of frying practices, and is able to distinguish above and below the established benchmark level of $500 \mu \mathrm{g} \mathrm{kg}{ }^{-1}$ for acrylamide.
\end{abstract}

\section{INTRODUCTION}

Acrylamide naturally originates mainly via Maillard reaction in starchy rich foods with low moisture level containing asparagine and reducing sugars when heated above $120^{\circ} \mathrm{C}$ (Biedermann et al. 2002; Mottram et al. 2002). According to the European Food Safety Authority (EFSA) Scientific Panel, potato fried products may significantly contribute to the total dietary acrylamide exposure in some population groups (EFSA 20I5). Acrylamide is classified by the International Agency for Research on Cancer (IARC) as a "probable human carcinogen' (Group 2A) (IARC 1994) and it was found in heat processed foods in 2002. In consequence, the General Food Law requires following up increased levels of any substance that would lead to a risk for the consumer (EU 2002). The potentially increased risk of developing cancer for the population of all age groups due to dietary exposure to acrylamide has been confirmed by EFSA (EFSA 2015). Recently, the European Commission Regulation 2017/2I58 established mitigation measures and benchmark levels for the reduction of acrylamide in food (EU Commission Regulation 2017).

After a prolonged monitoring EU programme launched by EFSA in 2007 and publication of various indicative values, the Regulation established a benchmark level of $500 \mu \mathrm{g} \mathrm{kg}^{-1}$ for French fries (ready-to-eat). The benchmark level reflects the trend in the industrial sector, including restaurants, after a decade of application of mitigation strategies (Food and Drug Administration Center for Food Safety and Applied Nutrition 2016; FDE 2019). However, these strategies cannot be directly extended to a private domestic setting since the main variables accounting for the process vary from home-to-home, or even individual-to individual (Langiano et al. 2012). In other words, there is a low degree of standardization, with little qualified supervision of the process to ensure reproducibility, traceability and good practices. Obviously, neither the hazard analysis and critical control points approach (HACCP) nor a food safety management system (FSMS) is implemented in most households.

The content of precursors in the potato tuber is pivotal to understand the extent of the acrylamide formation during the elaboration of French fries under controlled frying conditions (Ohara-Takada et al. 
2005; Palazoğlu and Gökmen 2008). In this regard, our research team highlighted the impact of the choice of the point of purchase of the fresh potatoes by the consumers on the exposure to acrylamide in a domestic setting under controlled frying conditions (Mesías et al. 2017). Results demonstrated that the reducing sugar content of the fresh tuber available in the supermarket largely influences the formation of acrylamide during deep frying. Due to the seasonality of this commodity, the reducing sugar content will vary depending on whether they are fresh harvested or stored (Muttucumaru et al. 2014). In late October, the availability of the current season's potatoes in the supermarkets decreases whereas the presence of stored potatoes increases gradually. The most unfavorable period to the Spanish consumer for the availability of potatoes intended for frying is April since nearly $60 \%$ of the potatoes in the supermarket have been stored long term.

Additionally, the uncertainty of the dietary exposure to acrylamide from French fries not only depends on the composition of the fresh tuber but the consumer practices during the food preparation. According to EFSA, in scenarios of home cooking, the total dietary exposure to acrylamide could be increased up to $80 \%$ depending on the conditions of potato frying (EFSA 20I5). In this context, observational studies are relevant to identify the effect of food handlers' decisions on the overall quality of foods, and more precisely for French fries, including the formation of acrylamide. It has been described that around $50 \%$ of the overall acrylamide intake of the population comes from the consumption of food prepared at home, in catering services and restaurants (Dybing et al. 2005). A research team from the Wageningen University evaluated the possible causes of variation in acrylamide concentration in French fries prepared in food service establishments (Sanny et al. 2012) and concluded that the training of food handlers is an effective strategy to reduce acrylamide formation (Sanny et al. 2013).

In a preliminary pilot study, our research group evaluated the potato handling and frying practices among 75 volunteers from three representative showed that $45.2 \%$ of the French fries prepared by the volunteers at home exceeded the benchmark level for French fries $\left(500 \mu \mathrm{gg}^{-1}\right)$, and $6.9 \%$ even exceeded $2000 \mu \mathrm{g} \mathrm{kg}^{-1}$ (Mesías et al. 2018a). Frying is an ancient culinary practice in Spain, and it is associated with the Mediterranean diet (Bastida and Sánchez-Muniz 20I5). The latest report on consumer habits in Spanish households describes that frying is the culinary practice applied to $17.3 \%$ of the meals prepared at home (Spanish Ministry of Agriculture, Fishering and Food 2019). However, not all the Spanish regions share the same frying habits (type of oil, kitchen appliance for frying, oil reusing, etc.) (Mesías et al. 20 I8b).

The present investigation aims not only to expand significantly the geographical area under study but also to include a new sampling during the early summer season. In this way, different culinary habits of Spanish households and differences linked to the seasonality of the potatoes in Spain will be considered. Results will be conclusive to assess the realistic contribution of consumer's cooking practices at home on the risk evaluation for acrylamide in French fries.

\section{MATERIALS AND METHODS}

\section{Chemicals and reagents}

Potassium hexacyanoferrate (II) trihydrate (98\%, Carrez-I) and zinc acetate anhydrous (>99\%, Carrez-II) were obtained from Sigma (St. Louis, USA). ${ }^{13} \mathrm{C}_{3}$-labelled acrylamide ( $99 \%$ isotopic purity) was obtained from Cambridge Isotope Laboratories (Andover, MA, USA). Formic acid (98\%), D(+)-glucose, methanol (99.5\%), hexane were from Panreac (Barcelona, Spain). Deionized water was obtained from a Milli-Q Integral 5 water purification system (Millipore, Billerica,MA, USA). All other chemicals, solvents and reagents were of analytical grade. 


\section{Study design}

A cohort of 208 validated volunteers was randomly recruited from 30 provinces of Spain located in 14 Autonomous Communities. Among the participating households, $87.5 \%$ were placed in cities with less than 500.000 habitants and 75 cases corresponded to municipalities with fewer than 50.000 habitants. Figure SI identifies the geographical location of households. They are distributed from the north $(n=95)$ to the south $(n=93)$ of the lberian Peninsula, and from the west $(n=97)$ to the east $(n=91)$. The province of Madrid was identified as the center $(n=20)$. Volunteers were asked to prepare a batch of French fries as they normally do and consume at home. They did not receive instructions concerning the variety and type of the potato, the preparation (peeling, cutting, soaking, blanching, etc.), the domestic frying appliance or the frying oil used. Therefore, a randomized scenario for consumer practices during the preparation of French fries was established. Volunteers were just instructed not to use deep-frozen par-fried French fries, and not to cut the fresh potatoes into thin slices for crisps. Participants were unaware of the purpose of the research and not informed in detail about the acrylamide issue in order to avoid any influence during the experiment. For the recruitment, no criterion related to the consumption frequency of fries was enforced. Volunteers provided passive consent prior to completing the study and did not receive any incentives for their participation. The study was conducted from I5 May to 15 June 2017.

\section{Sampling}

The validated procedure of Mesías et al. (2018a) was followed. Volunteers received a 'kit of sampling' containing a guidance with instructions (including photos), and containers properly coded to collect samples. Subjects were asked to select two homogeneous fresh potatoes without external damage from the same batch. One of them was kept as it was and wrapped in aluminium foil, and the other potato was used for frying. Each participant performed the frying procedure following their usual habits, including manipulation, selection of the kitchen appliance (pan-frying or deep-frying), potato/oil ratio, temperature, type of oil, as well as the decision on the end-point of frying. Once cooled, the fried potato and a portion of frying oil (ca. $25 \mathrm{~mL}$ ) were collected and frozen in the provided containers. Frozen samples were placed in an airtight freezer bag and couriered in a cool bag to the lab together with the fresh potato. After the reception, samples were photographed and stored at room temperature (fresh potatoes) and at $-20^{\circ} \mathrm{C}$ (frying oil and fried potatoes) until analysis.

\section{Questionnaire}

Volunteers were asked to fill out a questionnaire in order to characterize their sociodemographic profile, the type of households and their frying practices at home. The questionnaire was previously validated as described in Mesías et al. (2018a). Questions were structured in checkboxes with unique or multiple possible answers. The questionnaire was divided into seven different themes, according to i) sociodemographic information, ii) culinary habits (experience in cooking) and frequency of French fries consumption, iii) characteristics of potatoes intended for frying, iv) kitchen appliance and frying oil, v) practices related to the pre-frying stage, vi) frying stage (subjective ratio between the amount of potatoes with respect to the dimensions of the frying utensil: less than a half, a half, more than a half or full occupancy) and vii) practices related to the afterfrying stage. Participants agreed to the use of the data for the study.

\section{Characterization of fresh potatoes}

Potatoes were weighed and characterized by length and diameter with a calliper Etalon 125 (Rolle, Switzerland). The moisture content was determined gravimetrically after freeze-drying instead of oven drying due to the logistic limitations of the study in order to preserve the integrity of the fresh tuber. 


\section{Determination of reducing and total sugars}

The determination of the reducing sugar (glucose + fructose) content was performed as described by Miller (1959) with the modifications from Mesías et al (2017) as adapted to a plate-reader. Total sugar (glucose + fructose + sucrose) content was obtained after acid hydrolysis from sucrose to glucose and fructose. Results were expressed as $\mathrm{g}$ glucose equivalents $\mathrm{kg}$ of fresh sample ${ }^{-1}$. Limit of quantification (LoQ) was set at $0.6 \mathrm{~g}$ glucose equivalents $\mathrm{kg}$ sample $\mathrm{e}^{-1}$.

Asparagine determination by gas chromatography-flame ionisation detection (GC-FID)

The analysis was conducted according to Farkas and Toulouee (2003) with some minor modifications as described in Mesías et al. (2018a). The EZ:faast amino acid kit (Phenomenex, Torrance, USA) was used for quantitation of free asparagine in the potato tuber. The asparagine was quantified using GC-FID (Agilent GC 7820A FID) equipped with an automatic injector. An amino acid dedicated column (Zebron ZBAAA capillary; $10 \times 0.25 \mathrm{~mm}$ ) was used for the separation of amino acids. The oven was set to start at $110^{\circ} \mathrm{C}$ and increased $32^{\circ} \mathrm{C}$ per minute up to $320^{\circ} \mathrm{C}$. An aliquot of the derivatized sample $(\mathrm{I} \mu \mathrm{L})$ was injected at $250^{\circ} \mathrm{C}$ in split mode (15:I). The FID detector was set to $320^{\circ} \mathrm{C}$ and the carrier helium gas flow rate was kept at 1.5 $\mathrm{mL} \mathrm{min}^{-1}$ during the run. An external calibration was carried out with asparagine standard and results were corrected according to the recovery of norvaline, used as internal standard. Free asparagine content was expressed as $\mathrm{g} \mathrm{kg}$ of sample ${ }^{-1}$ (fresh matter).

\section{Determination of CIElab color}

Measurements were made at room temperature using a HunterLab Spectrophotometer CM-3500D colorimeter (Hunter Associates laboratory, Stamford, Connecticut, USA). Independent measurements of $a^{*}$ (redness), $b^{*}$ (yellowness) and $L^{*}$ (lightness) parameters were carried out on different areas of both fresh and fried potatoes as described by Mesías et al. (2018a).

\section{Determination of visual colour appearance and thickness}

Three untrained panellists classified the fried samples after a visual inspection with a subjective division. French fries were visually scored from the lightest to the brownest colour, and grouped as light-golden ( $\mathrm{n}=$ $21)$, golden $(n=102)$, dark-golden $(n=68)$ and toasted $(n=17)$. In addition, samples were classified according to the thickness of the fried potato, being thin ( $<5 \mathrm{~mm} ; \mathrm{n}=27$ ), medium (from 5 to $10 \mathrm{~mm} ; \mathrm{n}=$ I35) and thick (>10 mm; $\mathrm{n}=16)$.

\section{Acrylamide determination by liquid chromatography-electrospray ionisation-tandem mass spectrometry (LC-ESI-MS/MS)}

Acrylamide was determined in fried samples as described by Mesías and Morales (20I5). The recovery rate of acrylamide spiked to the samples was between $90 \%$ and $106 \%$. The relative standard deviations (RSD) for the precision, repeatability and reproducibility of the analysis were calculated as $2.8 \%, 1.2 \%$ and $2.5 \%$, respectively. The limit of the quantitation was set at $20 \mu \mathrm{gg}^{-1}$. The accuracy of the results was recently demonstrated for potato crisps and French fries in four proficiency tests launched by the Food Analysis Performance Assessment Scheme (FAPAS) programme, yielding a z-score of 0.2 (Test 3065, May-June 2016), -0.2 (Test 307I, February-March 20I7), 0.0 (Test 3085, Sep-20I8) and 0.3 (Test 3089, Feb-20I9). Results of acrylamide were expressed as $\mu \mathrm{g} \mathrm{kg} \mathrm{of} \mathrm{sample}{ }^{-1}$.

\section{Determination of polar compounds in oil}


Total polar compounds were measured in the frying oil by a hand-held device Testo 270 (Testo INC, New Jersey, USA) which is a rapid method based on the dielectric constant of the oil. Results were expressed as percentage of total polar material $\left(\mathrm{g} 100 \mathrm{~g} \mathrm{oil}^{-1}\right)$. Analysis was done in triplicate.

\section{Fatty acid composition}

Fatty acid composition of the frying oil was determined by the IUPAC Standard methods (IUPAC 1992). The following derivatisation to fatty acid methyl esters (FAMEs) with $2 \mathrm{M} \mathrm{KOH}$ in methanol, FAMEs were analysed by GC-6850 (Agilent Technologies, Palo Alto, CA, USA) equipped with an FID detector. FAMEs (c $=50 \mathrm{mg} \mathrm{mL}^{-1}$ in hexane, volume injected $\left.=2 \mu \mathrm{L}\right)$ were separated using HP Innowax capillary column $(30 \mathrm{~m}$ $\times 0.25 \mathrm{~mm}$ id, $0.25 \mu \mathrm{m}$ film thickness). The temperature program used was $180^{\circ} \mathrm{C}$ for $2 \mathrm{~min}$, followed by a $3^{\circ} \mathrm{C} \mathrm{min-I}$ increase to $230^{\circ} \mathrm{C}$ and held there for $20 \mathrm{~min}$. The temperatures of the injector and detector were held at $250^{\circ} \mathrm{C}$. Hydrogen was the carrier gas at a flow rate of $\mathrm{I} \mathrm{mL} \mathrm{min}{ }^{-1}$ with a split ratio of I:40. Proportions of fatty acids were determined as weight percentage.

\section{Statistical analysis}

Statistical analyses were performed using Statgraphics CenturionXV(Herndon, VA,USA) and SPSS version I6.0 (SPSS Inc., Chicago, IL). Results from at least two independent measurements were expressed as fresh weight. Raw data of acrylamide content was $\log _{10}$-transformed to improve the statistical analyses by the approximation to normal distributions of the data. The normality of the distribution was evaluated by the Kolmogorov-Smirnov test at $95 \%$ confidence level. T-student test and analysis of variance (ANOVA oneway) followed by Fisher's test were used to identify the overall significance of differences between variables. Differences among means were determined using Tukey's multiple range test. Homogeneity of variances was determined with the Levene test. Pearson linear correlation was applied to determine the relationship between variables and the strength was evaluated with the Pearson product moment correlation. Multivariate statistical analysis of the 208 scores was performed using the Principal Components Analysis to identify a limited number of variables for sample discrimination. All statistical parameters were evaluated at $P$ $<0.05$ significance level.

\section{RESULTS AND DISCUSSION}

\section{Participants and their practices of frying potatoes at home}

Two hundred and eight participants completed the study that includes the in-home frying test, and the filling of an ad-hoc questionnaire of frying practices. The characteristics of the participants, households and frying habits were obtained from the questionnaire. The use of par-fried frozen potatoes was avoided in the study since it limits the freedom of the consumer for the selection of the potato tuber, handling and several operations at the pre-frying step that would influence the level of acrylamide precursors.

The common profile within volunteers was a woman (75\%), between 36 and 55 years (53\%) with high experience in cooking (73\%). The household was mostly constituted by at least two persons (94\%) without individuals under 18 age (57\%). Most of the participants used a frying pan (78\%) and olive oil (78\%) as frying oil. The gender and age distribution, and other characteristics of the households (data not shown) are rather similar to those described by Mesías et al. (2018a) in the previous pilot study.

Regarding the consumer preferences, frequency and habits, participants declared to consume fries at least once per week (39\%), monthly (46\%) or exceptionally (15\%). They prefered to prepare French fries from fresh potatoes (86\%) instead of par-fried frozen potato (1\%). Participants stored the potatoes indoor (80\%) and washed the peeled potatoes before frying $(75 \%)$ but only a few volunteers applied a soaking step to the 
strips (23\%) before frying. According to the surface of the appliance (frying pan or frying basket), the amount of potato strips intended for frying was higher than the half of the dimension of the frying surface $(74 \%)$. Most of the volunteers added salt $(90 \%)$ to the potato, and mostly after frying $(53 \%)$. It is important to highlight that participants considered the color as the main criteria that determine the end-point of frying (89\%). They preferred the golden color (88\%) and fries crunchy on the outside and soft on the inside (83\%). The consumer practices for frying and the selection of parameters to assess the quality of the French fries were in line with the previous pilot study (Mesías et al. 2018a), regardless of the geographical location.

\section{Acrylamide in french fries prepared in households}

Acrylamide content in the 208 samples of French fries varied from 27 to $4200 \mathrm{\mu g} \mathrm{kg}^{-1}$ (Table I, Figure S2a). The mean value was $550 \mu \mathrm{g} \mathrm{kg}^{-1}$ (-469-630; 95\% confidence interval) and the median was $365 \mathrm{\mu g} \mathrm{kg}^{-1}$. The proportion of samples exceeding the acrylamide benchmark level of $500 \mathrm{\mu g} \mathrm{kg}^{-1}$ for French fries was $36.1 \%$ (European Commission 2017). Although the maximum value was $4200 \mu \mathrm{g} \mathrm{kg}^{-1}$, the $P 90$ was $1319 \mathrm{\mu g} \mathrm{kg}^{-1}$, and $75 \%$ of the samples contained acrylamide levels lower than $668 \mathrm{\mu g} \mathrm{kg}^{-1}$. The high coefficient of variation (107\%) and the standardised kurtosis (26.18) indicate the broadness of the data distribution. The data distribution exhibited one strong outlier $\left(4200 \mathrm{\mu g} \mathrm{kg}^{-1}\right.$; value $>3$-fold interquartile range), and three mild outliers (304I, 2773 and $225 \mathrm{I} \mathrm{\mu g} \mathrm{kg}^{-1}$; values $>1.5$-fold interquartile range) of the distribution (Figure S2a). These extreme values were also a consequence of the consumer cooking habits, and represent the heterogeneity of the culinary practices for the domestic preparation of French fries. Although the sample size $(n=208)$ was representative to perform a robust statistical analysis, the acrylamide dataset was further $\log _{10}$-transformed to obtain a normal distribution containing all data without exclusion. There are no significant differences between means for this study $\left(550 \mu \mathrm{kg}^{-1}\right)$ and the previous pilot study $\left(644 \mu \mathrm{g} \mathrm{kg}^{-1}\right)$ for the acrylamide content $(t=0.5207, p>0.05)$ (Mesías et al. 2018a).

\section{Factors affecting acrylamide content in French fries}

Asparagine and reducing sugars are well-known acrylamide precursors. The reducing sugar content is the limiting factor of acrylamide-forming potential in potato products (Becalski et al. 2004; Williams 2005). Asparagine content in fresh potatoes depends on factors like variety, location, fertilization, storage and processing. It is noteworthy the contribution of Rothamsted Research (UK) to identify the agronomic practices that might influence the levels of acrylamide precursors in potato cultivars (Muttucumaru et al. 2008). Asparagine content ranged from 0.45 to $6.63 \mathrm{~g} \mathrm{~kg}^{-1}$, with a mean value of $2.47 \mathrm{~g} \mathrm{~kg}^{-1}(2.34-2.60 \mathrm{~g}$ $\mathrm{kg}^{-1}$; $95 \%$ confidence interval) and a median of $2.37 \mathrm{~g} \mathrm{~kg}^{-1}$ (Table I, Figure S2b). The variability in the asparagine dataset represented only a variation of $38.53 \%$, with an interquartile range of $1.15 \mathrm{~g} \mathrm{~kg}^{-1}$. Half of the samples were in the interval from 1.83 to $2.97 \mathrm{~g} \mathrm{~kg}^{-1}$. The mean and median contents in asparagine were close to the previous study in the winter season, 2.65 and $2.54 \mathrm{~g} \mathrm{~kg}^{-1}$, respectively. There are no statistical differences of means between this study (early summer) and a previous study (winter) $(t=1.4 \mid 46, p>0.05)$ (Mesías et al. 2018a).

The reducing sugar content in fresh potatoes varies greatly and depends on the potato variety, maturity and storage conditions (Muttucumaru et al. 2014). Reducing sugars ranged from $<0.6 \mathrm{~g} \mathrm{~kg}^{-1}$ (LoQ) to $33.98 \mathrm{~g}$ $\mathrm{kg}^{-1}$, with a mean of $8.56 \mathrm{~g} \mathrm{~kg}^{-1}\left(7.47-9.66 \mathrm{~g} \mathrm{~kg}^{-1} ; 95 \%\right.$ confidence interval) and a median of $6.02 \mathrm{~g} \mathrm{~kg}^{-1}$ (Table I, Figure S2c). The variability in the reducing sugars dataset represented a coefficient of variation of $93.69 \%$, with an interquartile range of $11.34 \mathrm{~g} \mathrm{~kg}^{-1}$. Twenty samples $(9.6 \%)$ showed levels below the LoQ $\left(0.6 \mathrm{~g} \mathrm{~kg}^{-1}\right)$ and were considered as half of the LoQ for further statistical analysis. Fifty per cent of the observations were between 1.65 and $12.97 \mathrm{~g} \mathrm{~kg}^{-1}$. The median was significantly lower in the pilot study carried out during winter season $\left(2.86 \mathrm{~g} \mathrm{~kg}^{-1}\right)$ as compared with the current study and the previous one $(\mathrm{t}=$ 
-3.9977, $\mathrm{p}<0.000 \mathrm{I}$ ) (Mesías et al. 2018a). Four samples with reducing sugar content higher than $30 \mathrm{~g} \mathrm{~kg}^{-1}$ were identified as outliers (Figure S2c). Results for asparagine and reducing sugars are in line with the literature. Vivanti et al. (2006) reported asparagine $\left(0.15-7.62 \mathrm{~g} \mathrm{~kg}^{-1}\right)$ and reducing sugar content (0.5I$12.50 \mathrm{~g} \mathrm{~kg}^{-1}$ ) in 31 potato varieties commercialized in the USA and Italy. Elmore et al. (20I5) reported ranges for reducing sugars and asparagine of $0.18-21.25 \mathrm{~g} \mathrm{~kg}^{-1}$ and $0.15-1.24 \mathrm{~g} \mathrm{~kg}^{-1}$, respectively.

The first releases of the acrylamide toolbox recommended a reducing sugar content lower than $1.5 \%$ in dry weight base for fresh potatoes intended for French fries preparation. The Comitè national interprofessionnel de la pomme de terre (CNTP, Paris, France) settled the value of $0.32 \%$ for potato intended for frying among their associates for the campaigns from 2017 to 2020 . In the present study, $88.9 \%$ of the samples exhibited values higher than $0.3 \%$ whereas in the previous one only $43.8 \%$ (Mesías et al. 2018a). In June, the presence of season potatoes at the market is still low and they come from early potatoes harvested from March to June. Then, the presence of stored potato in the Spanish market is predominant in May, and starts to decrease in mid-June with the introduction of season potatoes. Therefore, the potatoes of the present assay could have been submitted to prolonged storage and very likely a process of starch degradation to single sugars is expected. It is well documented that temperatures below $6^{\circ} \mathrm{C}$ for long-term storage without an adequate re-conditioning step before frying lead to senescent sweetening caused by starch hydrolysis (De Wilde et al. 2005). In this sense, higher reducing sugar content in stored potatoes is prone to form higher levels of acrylamide during the frying process (FDE 2019). The Commission Regulation (EU) 2017/2I58 recommends special attention to the level of acrylamide in the finished product when the reducing sugar content is higher than $15 \mathrm{~g} \mathrm{~kg}^{-1}$.

The effect of the type of oil and its oxidative stability on acrylamide content in French fries was also evaluated. The participants collected a portion of the frying oil used for the preparation of the fried potatoes. Although the type of oil was recorded in the questionnaire, it was further confirmed analytically by their fatty acid composition. Samples were grouped in sunflower oil $(n=4 I)$, virgin olive oil $(n=12 I)$, olive oil $(n=39)$, blend oils $(n=6)$ and missing sample $(n=1)$. Frying stability of the oils depends on the presence of oxygen, the moisture content of the food, the temperature and the leaching of components from the food that yield of a high variety of products with different polarity, stability and molecular weight (Choe and Min 2007). These compounds contribute to the thermal oxidation and degradation of the frying oil constituents. The extent of the degradation also depends on the oil composition and the number of cycles of frying. Total polar compounds are oil degradation indicators because they refer to all degraded products that include polymeric triacylglycerols, oxidised-triacylglycerols, among others (Tabee et al. 2009). The maximum level of $25 \%$ polar compounds has been established as the upper limit of oil degradation for human consumption by most countries adopting regulations on frying fats and oils (Firestone 2007). In the present study, the mean content in polar compounds in the frying oil was $5.7 \mathrm{~g} \mathrm{l} 00 \mathrm{~g} \mathrm{oil}^{-1}(5.2-6.3 ; 95 \%$

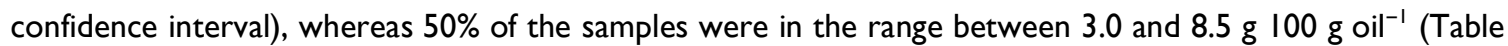
I, Figure S2d). There are no statistical differences between means $(t=0.7124, p>0.05)$ for the content in polar compounds between this assay and the pilot study carried in winter (Mesías et al. 2018a). The median content of polar compounds is low and indicates that most of the participants used fresh oil with few frying cycles, which is also compatible with the preference of using a panfrying instead of the electric fryer. Zhang et al. (2015) confirmed that acrylamide in French fries did not increase significantly with an increase in the number of frying cycles. In contrast, a significant relationship was not observed between the content of polar compounds and the different types of frying devices. However, there is a significant relationship between the polar compound content and the type of frying oil used (F-ratio $=34.43 ; p<0.000 I)$. The lowest content in 
polar compounds was for olive virgin oil (3.96\%), followed by olive oil (5.31\%), blends (8.6) and sunflower oil $(10.83 \%)$.

The participants identified the color of French fries as the pivotal quality parameter to decide the end-point of the frying. The distribution of the color parameters (E-index, $\left.L^{*}, a^{*}, b^{*}\right)$ in both fresh and fried potatoes is described in Table I. Taken all dataset at once, the luminosity $\left(L^{*}\right)$ tended to decrease as well as the $E$ index in the fried potatoes. The value of the chromatic parameters $a^{*}$ and $b^{*}$ increased significantly in the fried potatoes. The literature describes the correlation between color parameter $a^{*}$ and the formation of acrylamide in French fries (Pedreschi et al. 2005, 2006, 2007; Gökmen et al. 2007; Mesías et al. 2017, 20I8a, 2019). The distribution of color parameter $a^{*}$ in the fried potato is depicted in Figure S3a. The mean value of parameter $\mathrm{a}^{*}$ in fried potatoes was 1.46 (I.I0-I.8I; $95 \%$ confidence interval), whereas $50 \%$ of the samples were in the range between $-0.6 \mathrm{I}$ and 3.34 .

The experimental design compiles direct (chemical and physical analyses) and indirect (frying practices obtained from the questionnaire) information of the variables involved at the different steps of the frying process. The measurement of the reducing sugars and asparagine in the potato tuber gives direct information about the level of acrylamide precursors. Similarly, the color parameters ( $\left.L^{*}, a^{*}, b^{*}\right)$ provide quantitative information on the progress of the reaction. The operations of the participants for the preparation of the strips before frying and the frying conditions were obtained from the questionnaire. The thermal input and the extent of the process were assessed indirectly from the weight loss of the sample (Figure S3b). The mean moisture of the fresh potatoes was $80.09 \%$ (79.63-80.55; 95\% confidence interval), and one sample was identified as an outlier with extremely low moisture content (66.02\%). The mean moisture content of the fried potatoes was $58.99 \%$ (57.94-60.05; $95 \%$ confidence interval). The weight loss for each independent sample was calculated to be $21.15 \%$ (20.14-22.16; 95\% confidence interval), whereas $50 \%$ of the samples were in the range between $16.16 \%$ and $25.66 \%$. There was not a significant relationship between the initial moisture content in fresh potatoes and the final moisture content in fried products.

Chemometric analysis of the dataset was performed through Principal Component Analysis (PCA) that represents a useful exploratory tool to evaluate the ability of measured parameters to differentiate groups of samples through a data visualization technique. Three principal components (PCs) with eigenvalues $>$ I, which explain $72.5 \%$ of the total variance, were extracted. Figure I shows the standardized loading plot of the variables corresponding to the first two eigenvectors, which concentrate $56.6 \%$ of the total variance (PCI: $33.7 \%$ and PC2: $22.9 \%)$. The $\mathrm{PCl}$ is negatively associated with the weight loss $(-0.4238)$ and the color parameter E (-0.5247) and positively associated with the reducing sugar content $(0.4134)$ and moisture of fried potato $(0.480 \mathrm{I})$. The PC2 is positively associated with the acrylamide $(0.5797)$ and color parameter a* $(0.5315)$, but there is no contribution of the reducing sugars. Total polar compounds and asparagine did not contribute to the explanation of the variability of the 208 scores. Bivariate correlation analysis was used to investigate more in detail the strength and direction of the relationship among the different quantitative variables (Table 2). Asparagine, sugars (sucrose + glucose + fructose), reducing sugars (fructose + glucose) and moisture of fresh potatoes; polar compounds in the frying oil; moisture, color parameters (E, L*, $\left.a^{*}, b^{*}\right)$, acrylamide in fried potatoes; the weight loss of fried potatoes and the total polar compounds in the frying oil were considered. Acrylamide was not significantly correlated with its precursors in the potato tuber. As previously stated by Mesías et al. (2018a), the consumer' frying practices are a substantial source of variability in this randomized trial. Although sugars in the fresh tuber directly affect the acrylamide content under controlled laboratory conditions (Ohara-Takada et al. 2005; Palazoğlu and Gökmen 2008), several factors related to consumer practices might contribute as well (Mesías et al. 2017). Acrylamide content was 
significantly correlated with the color parameters $\mathrm{E}$ and $\mathrm{L}^{*}$, showing the strongest correlation with the color parameter $a^{*}(r=0.6120 ; p<0.0001)$. Furthermore, the concentration of acrylamide precursors in the potato tuber does not predict the acrylamide content reached in the fries.

Definitively, the food handler's decision on the final color will influence the acrylamide content, and consequently on the exposure to acrylamide from French fries.

It is noteworthy to mention the significant relationship between the reducing sugar content with the weight loss and the color parameter $\mathrm{E}$ (Table 2). Higher reducing sugar content is inversely related to weight loss and color, and consequently, participants prefer to cook less the potato with higher reducing sugar to avoid dark color in the product. The golden color was identified as the principal descriptor to set the end of frying. Regardless of the content in precursors, participants modulate the extension of the frying to reach the target color. In agreement with the participant's decision, there is a strong significant relationship between color $E$ and the weight loss that support the previous statement $(p<0.0001)$, and a trend between acrylamide and weight loss $(\mathrm{p}=0.0532)$. Participants do not distinguish between the variation of a specific color (i.e. redness), but they use the overall browning of the potato as an index to identify when the potato is done. To go deeper into this aspect, participants were asked to classify the visual appearance of their fries without a reference. Seventy-eight per cent $(n=159)$ of the responders classified their fries as golden (three participants did not provide a response). In parallel and taken all samples together, French fries were classified in light-golden, golden, dark-golden and toasted by a group of panelists. It was relevant to notice that $17 \%$ of the light-golden, $35 \%$ of the dark-golden and $3 \%$ of the toasted samples were identified as golden by the participants' criteria based on visual appearances. It is possible that certain consumer was not willing to compromise a personal hedonic experience for dark-golden or even toasted fries, instead of decreasing a potential toxicological risk. These results support the educational initiatives undertaken from different sectors orientated to consumers in order to associate the extent of browning of French fries with the mitigation strategies for acrylamide at home. Examples are the 'go for gold' campaign launched by UK's Food Standard Agency, acrylamide pamphlets on the European Commission and the EFSA websites, and the slogan 'dorado, pero no pasado' (golden, but no further) by the Spanish Agency for Food Safety in 2017. The results confirm those consumers need a clearer definition for the 'golden' concept in order to develop scientific-based color guides.

Since there is a strong correlation between acrylamide and the colour parameters (Table 2), further investigations were focused on identifying useful criteria for the golden concept based on the visual colour appearance of French fries. Figure 2(a) shows the acrylamide distribution in each group of French fries and the level of significance. Significant differences between groups were found $(F=63.75, p<0.000 \mathrm{I})$ (Table $\mathrm{SI})$. The ANOVA analysis is also robust enough to identify the same differences among groups by applying directly the acrylamide data without $\log _{10}$-transformation $(F=53.88, p<0.0001)$. The four groups of visual color appearance were significantly different that correspond to light-golden (I0I, 80-126 $\mu \mathrm{g} \mathrm{kg}^{-1}$; mean, lower and upper limit), golden (238, 215-263 $\left.\mu \mathrm{gg}^{-1}\right)$, dark-golden (587, 519-665 $\left.\mu \mathrm{g} \mathrm{kg}^{-1}\right)$ and toasted (I53I, I195-1963 $\mathrm{\mu g} \mathrm{kg}^{-1}$ ). Since the Regulation for acrylamide indicates a benchmark level of $500 \mu \mathrm{g} \mathrm{kg}{ }^{-1}$ for French fries (European Commission 2017), samples were sorted according to their acrylamide content (above or below $500 \mu \mathrm{g} \mathrm{kg}^{-1}$ ). The percentages of samples with acrylamide content higher than the benchmark level for each visual color appearance were $4.8 \%, 21.6 \%, 51.5 \%$ and $100 \%$ for light-golden, golden, dark-golden and toasted, respectively. These results confirm that an adequate and trained visual inspection reveals as the first option to mitigate the acrylamide exposure from fried potatoes in a domestic setting. However, nearly half of the samples did not follow this rule in the subset of samples classified as dark-golden color. Therefore, there are other variables that could affect the misclassification of the samples. 
Color appearance occurs in the crust of the potato and is strongly associated with the acrylamide content. However, acrylamide content in the whole fried strip also depends on the thickness and the homogeneous distribution of darkening. For similar color appearance, it is expected lower acrylamide content in a thick potato strip, where the core is still moist compared with a thin strip. In this sense, strips that darken homogeneously tend to present acrylamide content lower than that in potatoes darkened with spots. In this study, $\mathbf{7 9 . 5 \%}$ of the samples that depicted a homogeneous color distribution at the surface had acrylamide levels lower than the EU benchmark level.

\section{Suitability of the chromatic parameter $a^{*}$}

The visual colour appearance was strongly correlated with the chromatic parameter $a^{*}$, and the ANOVA analysis was able to discriminate satisfactorily $(F=106.89, p<0.0001$, Table 3$)$ among the different classes of the visual colour appearance of French fries (Figure 2(b)). The dataset for colour a* fits a normal distribution and $\log _{10}$-transformation was not necessary. The mean and confidence intervals at $95 \%$ for a* were - I.54I (-2.194- -0.887), 0.312 (0.016-0.609), 2.900 (2.535-3.26I) and 6.274 (5.547-7.000) for lightgolden, golden, dark-golden and dark, respectively.

Figure 3(a) depicts the distribution of the dataset of colour parameter $a^{*}$ in the two levels of acrylamide $\left(<500 \mu \mathrm{kg}^{-1},>500 \mu \mathrm{kg}^{-1}\right)$. Means between groups are significantly different $(\mathrm{t}=-4.8, \mathrm{p}<0.000 \mathrm{I}$, Table 3 ), which corroborates the strong relationship between the parameter $a^{*}$ and the formation of the contaminant. This relation is also revealed in the samples grouped by the visual colour appearance and distributed according to the parameter $\mathrm{a}^{*}$ and the acrylamide content (Figure 3(b)). The darkening of the French fries, and, therefore, higher levels of the chromatic parameter $a^{*}$, implies the greater formation of acrylamide. The control of the extent of browning during the frying is also effective for controlling the formation of acrylamide in the domestic setting. Definitely, and for educational purposes, it is useful to settle criteria for the concept 'golden' colour based on the visual colour appearance of French fries that is connected with the benchmark level for French fries established by the EU Regulation 2017/2158.

\section{CONCLUSIONS}

In terms of Food Safety, the reduction of potentially health-threatening compounds in foods at levels as low as reasonably achievable is an objective. The involvement of the producers as well as any intermediate partner in the chain is necessary. However, in the specific case of chemical processing contaminants, the consumer practices during food preparation are pivotal to reduce dietary exposure. Nevertheless, the administration and the private sector have a joint responsibility to achieve this goal. The food industry sector self-regulated before EU 2017/2I58 with tailored initiatives as the Acrylamide Toolbox, but the primary sectors need to be involved as well in order to provide consumers with the most adequate raw material for specific culinary preparations, in terms of lower content in acrylamide precursors. The contribution of the Rothamsted Research (UK) is noteworthy in identifying the agronomic practices that might influence the levels of acrylamide precursors in potato cultivars. Differences in consumer practices towards acrylamide reduction in fries were explored. The potato handling and frying practices during the preparation of home-cooked French fries are considered as a source of variability for the acrylamide, and consequently for the dietary exposure of consumers. This randomized study ( $n=208$ cases) complements the pilot study carried out previously during winter $(n=73$ cases). There were no significant differences between both studies for acrylamide content, being 550 and $644 \mu \mathrm{g} \mathrm{kg}^{-1}$ in the early summer (May-June) and the winter study (November-December), respectively. The reducing sugar content was significantly higher in the present study, as compared with the winter study, $8.56 \mathrm{~g} \mathrm{~kg}^{-1}$ and $2.86 \mathrm{~g} \mathrm{~kg}^{-1}$, respectively. No impact of the frying oil was observed on the results for acrylamide. The chromatic parameter $a^{*}$ was able to sort 
the samples with high $\left(>500 \mu \mathrm{gg}^{-1}\right)$ and low $\left(<500 \mu \mathrm{g} \mathrm{kg}^{-1}\right)$ acrylamide content, regardless of the potato variety and storage conditions, pre-frying operations or frying conditions applied by the consumer. Regardless of the starting levels of precursors, participants modulate the length of frying to reach the objective of the desired color. A total of $78 \%$ of the participants classified the fried potatoes as 'golden', but a harmonized classification indicated that nearly $40 \%$ were overcooked. In the light of the results of this investigation, the authorities should reinforce the educational initiatives intended to consumer and food handlers in terms of adequate frying habits. These initiatives might be also accompanied by food manufacturers' instruction, as well as from kitchen appliance manufactures, in order to set the frying parameters for a healthier preparation of French fries.

\section{ACKNOWLEDGEMENTS}

The authors thank Ms. I. Alvarez, Ms. B. Díaz and Mr. M.A. Martinez for their technical assistance, and Dr. J. Martinez-Monzó and Dra. P. García for the validation of the questionnaire.

\section{Disclosure statement}

No potential conflict of interest was reported by the authors.

\section{Funding}

This research is funded by the Ministry of Economy and Competitiveness (Spain) under project SAFEFRYING (AGL2015-46234-R).

\section{ORCID}

M. Mesias http://orcid.org/0000-0003-0905-1587

C. Delgado-Andrade http://orcid.org/0000-0002-5748-8583

F. J. Morales http://orcid.org/0000-0003-3984-7009

\section{REFERENCES}

Bastida S, Sánchez-Muniz FJ. 2015. Frying: a cultural way of cooking in the Mediterranean Diet. In: Preedy VR, Watson RS, editors. The mediterranean diet. An evidence based approach. London (UK): Academic Press; p. 217-234.

Becalski A, Lau BPY, Lewis D, Seaman SW, Hayward S, Sahagian M, Ramesh M, Leclerc Y. 2004. Acrylamide in French fries: influence of free amino acids and sugars. J Agric Food Chem. 52(I2):380 I-3806.

Biedermann M, Biedermann-Brem S, Noti A, Grob K. 2002. Methods for determining the potential of acrylamide formation and its elimination in raw materials for food preparation, such as potatoes. Mitt Lebensm Hyg. 93:653-667.

Choe E, Min DB. 2007. Chemistry of deep-fat frying oils. J Food Sci. 72(5):77-86.

De Wilde T, De Meulenaer B, Mestdagh F, Govaert Y, Vandeburie S, Ooghe W, Fraselle S, Demeulemeester K, Van Peteghem C, Calus A, et al. 2005. Influence of storage practices on acrylamide formation during potato frying. J Agric Food Chem. 53(16):6550-6557.

Dybing E, Farmer PB, Andersen M, Fennell TR, Lalljle SPD, Muller DJG, Olin S, Peterson BJ, Schlatter J, Scholz G, et al. 2005. Human exposure and internal dose assessments of acrylamide in food. Food Chem Toxicol. 43 (3):365-4I0.

[EFSA] European Food Safety Authority. 2015. Scientific opinion on acrylamide in food. EFSA J. 13(6):4104. Elmore JS, Briddon A, Dodson AT, Muttucumaru N, Halford NG, Mottram DS. 2015. Acrylamide in potato crisps prepared from 20 UK-grown varieties: effects of variety and tuber storage time. Food Chem. 182:I-8. 
[EU] European Commission. 2002. Commission Regulation (EU) 178/2002 of 28 January 2002 laying down the general principles and requirements of food law, establishing the European Food Safety Authority and laying down procedures in matters of food safety. Off J Eur Commun. L3I:I-24.

European Commission. 2017. Commission Regulation (EU) 2017/2158 of 20 november 2017 establishing mitigation measures and benchmark levels for the reduction of the presence of acrylamide in food. OJEU. L304:24-44.

Farkas T, Toulouee J. 2003. Asparagine analysis in food products. LC GC Eur. 21:14-16.

[FDA] Food and Drug Administration Center for Food Safety and Applied Nutrition. 2016. Guidance for industry acrylamide in foods; [accessed 2019 Jun 30]. https://www.fda.gov/regulatory-information/search-fdaguidancedocuments/guidance-industry-acrylamide-foods.

[FDE] Food Drink Europe. 2019. The acrylamide toolbox 15th edition; [accessed 2019 Jun 30].

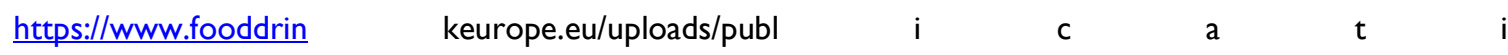
ons_documents/FoodDrinkEurope_Acrylamide_Toolbox_2019.pdf.

Firestone D. 2007. Regulation of frying fats and oils. In: Erickson MD, editor. Deep frying: chemistry nutrition and practical applications. 2nd ed. Champaign (IL): AOCS Press; p. 373-385.

[IUPAC] International Union of Pure and Applied Chemistry. 1992. Standard methods for the analysis of oils, fats and derivatives. 7th ed. International Union of Pure and Applied Chemistry. Oxford (UK): Blackwell Scientific.

[IARC] International Agency for Research on Cancer. 1994. Some industrial chemicals. IARC Monographs on the evaluation for carcinogenic risk of chemicals to humans. Vol. 60. Lyon (France): IARC; 435-453.

Gökmen V, Senyuva HZ, Dülek B, Çetin AE. 2007. Computer vision-based image analysis for the estimation of acrylamide concentrations of potato chips and French fries. Food Chem. 101(2):791-798.

[MAPAMA] Spanish Ministry of Agriculture, Fishering and Food. 2019. Report on food consumption in Spanish households. [accessed 2019 Jun 30]. https://www.mapa.gob.es/en/alimentacion/temas/consumo-ycomercializacion-y-distribucion-alimentaria/20190624_informedeconsumo2018pdf_tcm38-510816.pdf.

Langiano E, Ferrara M, Lanni L, Viscardi V, Abbatecola AM, De Vito E. 2012. Food safety at home: knowledge and practices of consumers. Zeitschrift Fur Gesundheitswissenschaften. 20 (I):47-57.

Mesias M, Delgado-Andrade C, Holgado F, Morales FJ. 2019. Acrylamide content in French fries prepared in food service establishments. LWT Food Sci Technol. 100:83-91.

Mesías M, Delgado-Andrade C, Holgado F, Morales FJ. 2018a. Acrylamide content in French fries prepared in households: A pilot study in Spanish homes. Food Chem. 260:44-52.

Mesías M, Delgado-Andrade C, Morales FJ. 2018b. Evaluation of domestic frying habits and consumer's preferences in Spanish households. SDRP J Food Sci Technol. 3(5):450-459.

Mesías M, Holgado F, Márquez-Ruiz G, Morales FJ. 2017. Impact of the characteristics of fresh potatoes available in-retail on exposure to acrylamide: case study for French fries. Food Control. 73:1407-1414.

Mesías M, Morales FJ. 2015. Acrylamide in commercial potato crisps from Spanish market: trends from 2004 to 2014 and assessment of the dietary exposure. Food Chem Toxicol. 81:104-110.

Miller GL. 1959. Use of dinitrosalicylic acid reagent for determination of reducing sugars. Anal Chem. $31: 426-428$.

Mottram DS, Wedzicha BI, Dodson AT. 2002. Acrylamide is formed in the Maillard reaction. Nature. 419:448.

Muttucumaru N, Elmore JS, Curtis T, Mottram DS, Parry MAJ, Halford NG. 2008. Reducing acrylamide precursors in raw materials derived from wheat and potato. J Agric Food Chem. 56(I5):6167-6172.

Muttucumaru N, Powers SJ, Elmore JS, Briddon A, Mottram DS, Halford NG. 2014. Evidence for the complex relationship between free amino acid and sugar concentrations and acrylamide-forming potential in potato. Ann Appl Biol. 164(2):286-300. 
Ohara-Takada A, Matsuura-Endo C, Chuda Y, Ono H, Yada H, Yoshida M, Kobayashi A, Tsuda S, Takigawa $\mathrm{S}$, Noda T, et al. 2005. Change in content of sugars and free amino acids in potato tubers under short-term storage at low temperature and the effect on acrylamide level after frying. Biosci Biotechnol Biochem. 69(7): 1232-1238.

Palazoğlu TK, Gökmen V. 2008. Development and experimental validation of a frying model to estimate acrylamide levels in French fries. J Food Sci. 73(3): EI09-EI I4.

Pedreschi F, Kaack K, Granby K. 2006. Acrylamide content and color development in fried potato strips. Food Res Int. 39:40-46.

Pedreschi F, León J, Mery D, Moyano P, Pedreschi R, Kaack K, Granby K. 2007. Color development and acrylamide content of pre-dried potato chips. J Food Eng. 79:786-793.

Pedreschi F, Moyano P, Kaack K, Granby K. 2005. Color changes and acrylamide formation in fried potato slices. Food Res Int. 38: I-9.

Sanny M, Jinap S, Bakker EJ, van Boekel MAJS, Luning PA. 2012. Possible causes of variation in acrylamide concentration in French fries prepared in food service establishments: an observational study. Food Chem. 132 (I):134-143.

Sanny M, Luning PA, Jinap S, Bakker EJ, van Boekel MAJS. 20I3. Effect of frying instructions for food handlers on acrylamide concentration in French fries: an explorative study. J Food Prot. 76(3):462-472.

Tabee E, Jägerstad M, Dutta PC. 2009. Frying quality characteristics of French fries prepared in refined olive oil and palm olein. J Am Oil Chem Soc. 9 (86):885-893.

Vivanti V, Finotti E, Friedman M. 2006. Level of acrylamide precursors asparagine, fructose, glucose, and sucrose in potatoes sold at retail in Italy and in the United States. J Food Sci. 7I(2):C8I-C85.

Williams JSE. 2005. Influence of variety and processing conditions on acrylamide levels in fried potato crisps. Food Chem. 90(4):875-88I.

Zhang H, Zhang H, Cheng L, Wang L, Qian H. 20I5. Influence of deep-frying using various commercial oils on acrylamide formation in French fries. Food Addit Contam Part A. 32(7): 1083-1088. 


\section{FIGURES AND TABLES}

Table I. Descriptive analysis of numerical variables for fresh potato (asparagine, reducing sugars, moisture, color Hunter-Lab), frying oil (total polar compounds) and fried potato (acrylamide, moisture, color HunterLab).

\begin{tabular}{|c|c|c|c|c|c|c|c|c|}
\hline & Mean & Min & Max & QI & Median & Q3 & $\mathbf{P}_{90}$ & $\mathbf{P}_{95}$ \\
\hline \multicolumn{9}{|l|}{ Fresh potato } \\
\hline Asparagine $\left(\mathrm{g} \mathrm{kg}^{-1}\right)$ & 2.47 & 0.45 & 6.63 & 1.83 & 2.37 & 2.97 & 3.93 & 4.23 \\
\hline Reducing sugars ( $\left.\mathrm{g} \mathrm{kg}^{-1}\right)$ & 8.56 & $<$ LoQ & 33.98 & 1.65 & 6.02 & 12.97 & 20.10 & 24.70 \\
\hline Moisture (\%) & 80.10 & 66.02 & 86.18 & 77.73 & 80.61 & 82.58 & 84.09 & 84.59 \\
\hline $\mathrm{E}^{*}$ & 64.81 & 54.87 & 73.17 & 62.55 & 64.94 & 66.72 & 69.02 & 70.25 \\
\hline$L^{*}$ & 62.33 & 53.07 & 71.75 & 60.42 & 62.40 & 64.27 & 66.04 & 67.12 \\
\hline$a^{*}$ & -1.22 & -2.39 & 1.23 & -1.72 & -1.35 & -0.85 & -0.24 & 0.24 \\
\hline$b^{*}$ & 17.27 & 8.23 & 29.37 & 14.50 & 17.27 & 19.93 & 22.44 & 23.54 \\
\hline \multicolumn{9}{|l|}{ Frying oil } \\
\hline Polar compounds (\%) & 5.7 & 1.8 & 24.0 & 3.0 & 4.0 & 8.5 & 11.5 & 13.7 \\
\hline \multicolumn{9}{|l|}{ Fried potato } \\
\hline Acrylamide $\left(\mu \mathrm{g} \mathrm{kg}^{-1}\right)$ & 550 & 27 & 4200 & 162 & 365 & 668 & 1319 & 1747 \\
\hline Moisture (\%) & 59.0 & 34.4 & 77.6 & 53.9 & 60.2 & 64.6 & 67.8 & 73.7 \\
\hline $\mathrm{E}^{*}$ & 62.93 & 48.18 & 74.90 & 58.70 & 63.63 & 67.33 & 70.59 & 71.64 \\
\hline$L^{*}$ & 59.32 & 44.06 & 71.41 & 55.46 & 60.08 & 63.6 & 66.95 & 67.48 \\
\hline$a^{*}$ & 1.46 & -3.45 & 8.98 & -0.61 & 1.1 & 3.34 & 4.69 & 6.06 \\
\hline$b^{*}$ & 20.38 & 9.48 & 29.46 & 18.24 & 20.34 & 22.64 & 24.6 & 26.29 \\
\hline
\end{tabular}

$\mathrm{LoQ}=0.6 \mathrm{~g} \mathrm{~kg}^{-1}$. 
Table 2. Pearson correlation coefficients $(r)$ and level of significance $(p)$ between the studied quantitative variables in the fresh/fried potato and frying oil.

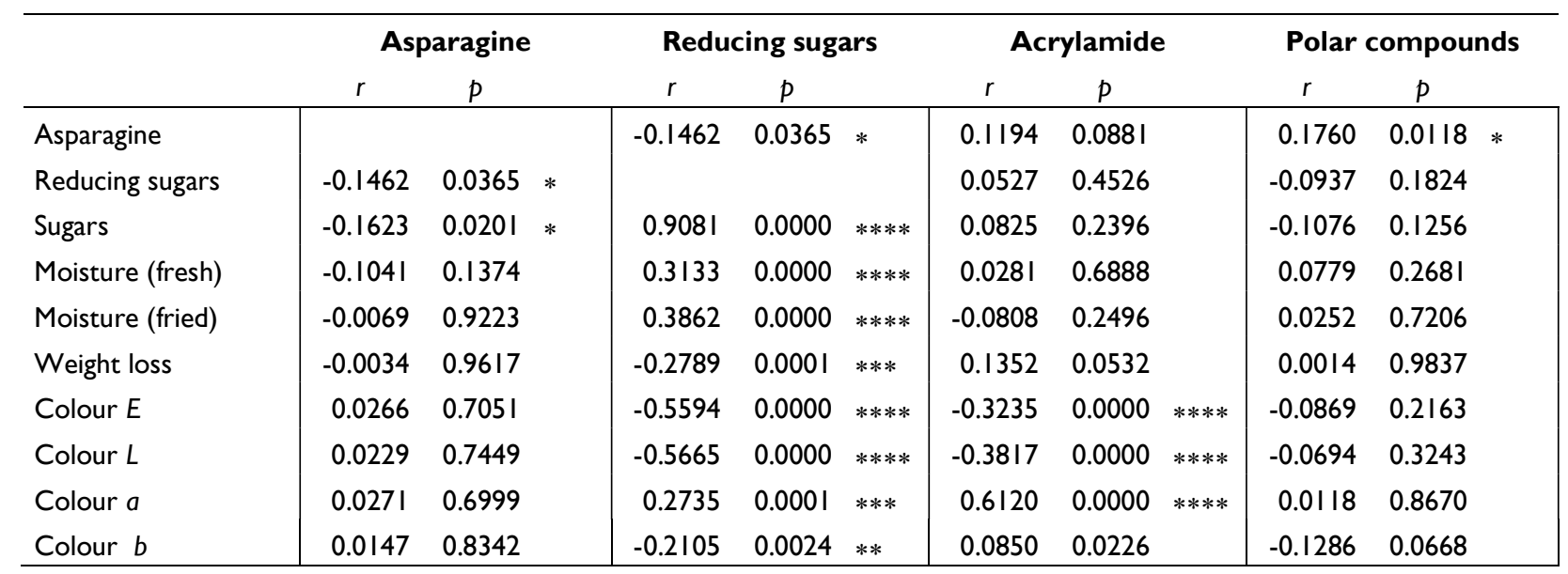

$*(\mathrm{p}<0.05) ; * *(\mathrm{p}<0.0 \mathrm{I}) ; * * *(\mathrm{p}<0.00 \mathrm{I}) ; * * *(\mathrm{p}<0.000 \mathrm{I})$ 
Table 3. One-way ANOVA test and Student's t-test to establish the effect of studied variables (visual appearance and acrylamide level) on the color parameter a*. LL (lower) and UL (upper) limits at the $95 \%$ of confidence interval.

\begin{tabular}{lllllll}
\hline Factor & mean & LL & UL & group & F-ratio & p-value \\
\hline visual appearance & & & & & 106.890 & 0.0000 \\
light-golden & -1.5410 & -2.0386 & -1.0433 & $\mathrm{a}$ & & \\
golden & 0.3128 & 0.0870 & 0.5386 & $\mathrm{~b}$ & & \\
dark-golden & 2.8979 & 2.6214 & 3.1745 & $\mathrm{c}$ & & \\
toasted & $6.274 \mathrm{I}$ & 5.7210 & 6.8272 & $\mathrm{~d}$ & & \\
\hline Factor & mean & LL & UL & group & t & p-value \\
\hline acrylamide level & & & & & -4.88 & 0.0000 \\
$<500 \mu \mathrm{g} \mathrm{kg-1}$ & -0.4060 & $-0.045 \mathrm{I}$ & 0.8572 & $\mathrm{a}$ & & \\
$>500 \mu \mathrm{kg} \mathrm{kg}^{-1}$ & 2.1269 & 1.6470 & 2.6062 & $\mathrm{~b}$ & & \\
\hline
\end{tabular}


Fig. I. Principal component loading plot applied to a dataset of 208 samples of French fries prepared in a domestic setting. PCI+PC2 (56.6\%). Variables for fresh potato (open circle); variables for fried potato (solid circle).

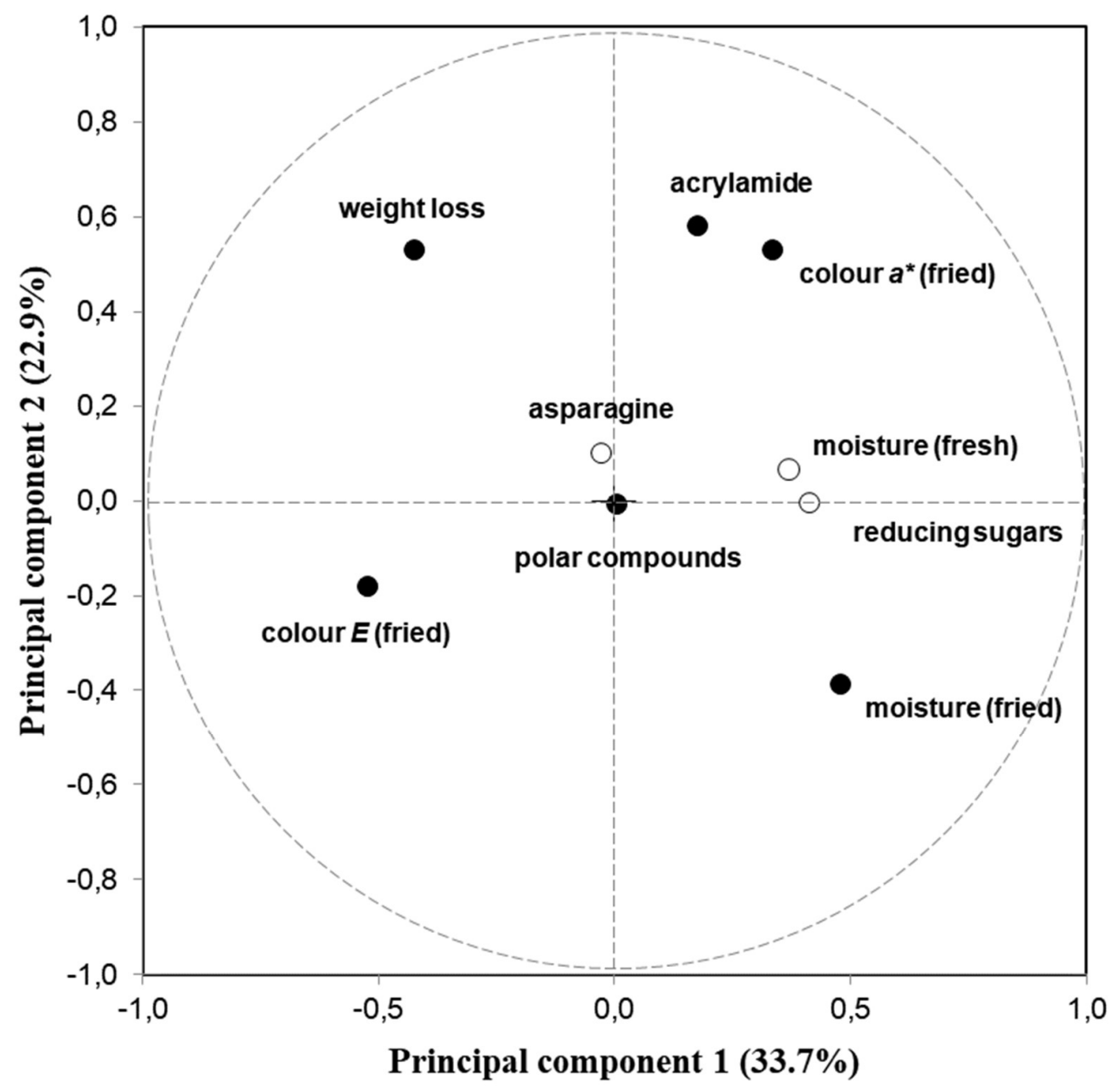


Fig. 2. Box-plot of acrylamide ( $\left.\mu \mathrm{kg}^{-1}\right)$ (a) and color $\mathrm{a}^{*}$ (b) for the classification of French fries according to the visual color appearance (light-golden, golden, dark-golden and toasted). Different letters mean significant differences between groups.
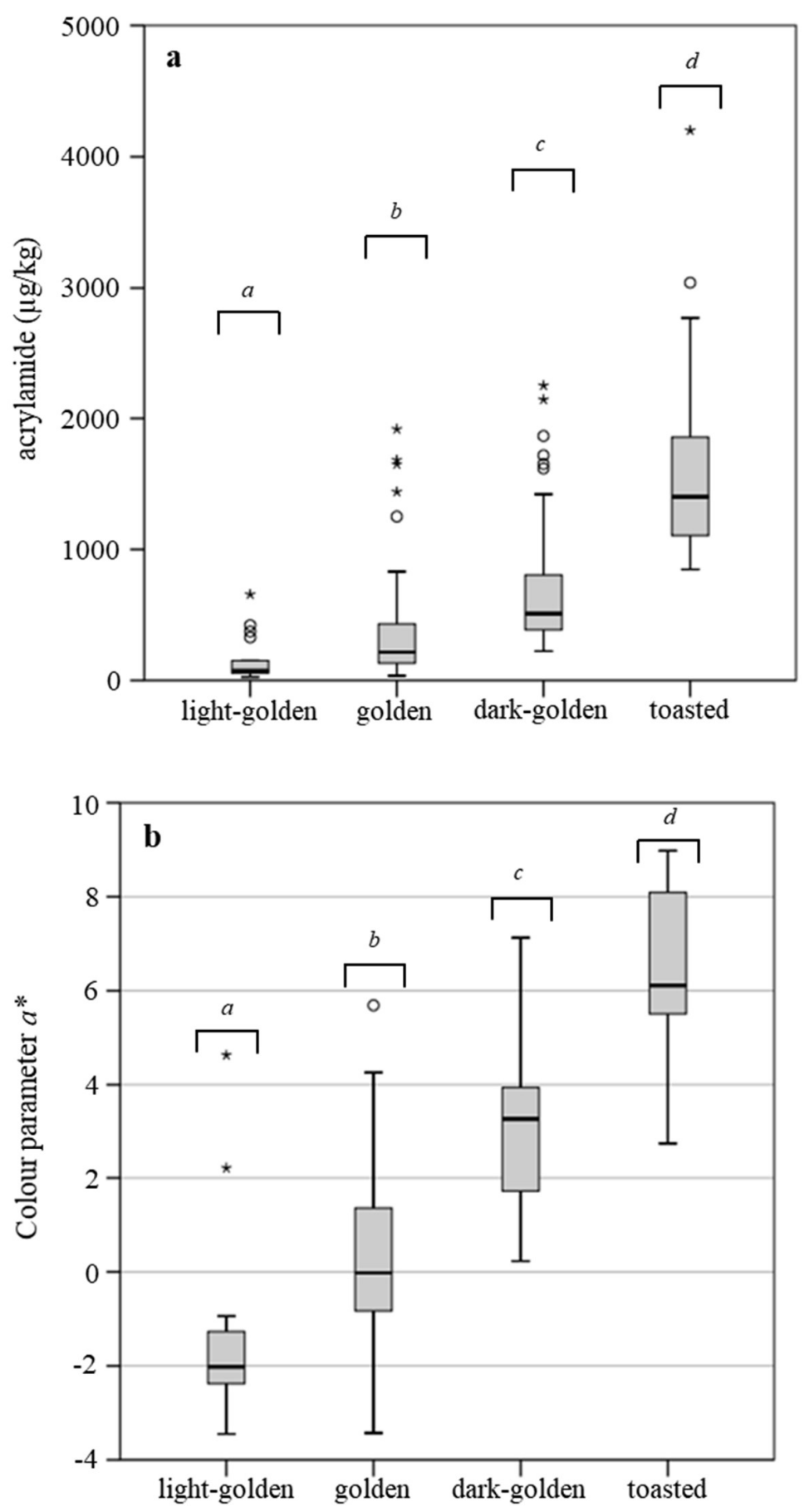
Fig. 3. Relationship between parameter $\mathrm{a}^{*}$ (HunterLab) and the acrylamide threshold for French fries lower $(<500)$ or higher $(>500)$ than $500 \mu \mathrm{gg}^{-1}(\mathrm{a})$, and direct relationship between parameter a* and acrylamide (b). Dots are sorted by visual color appearance (light-golden, golden, dark-golden, toasted).
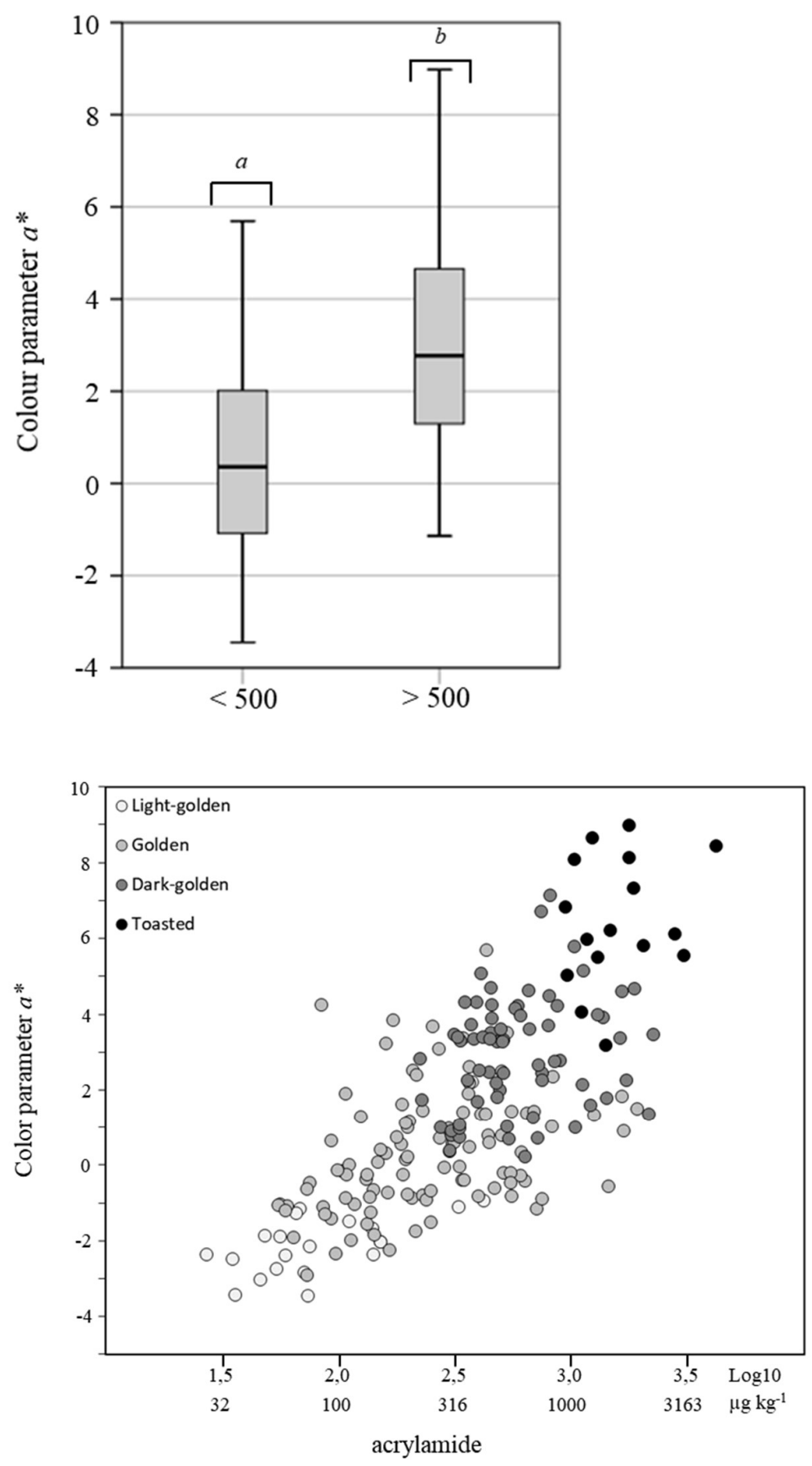
Figure SI. Geographical distribution of the households in 30 Spanish provinces of the lberian Peninsula. Black (centre), pale-grey (south), dark-grey (north).

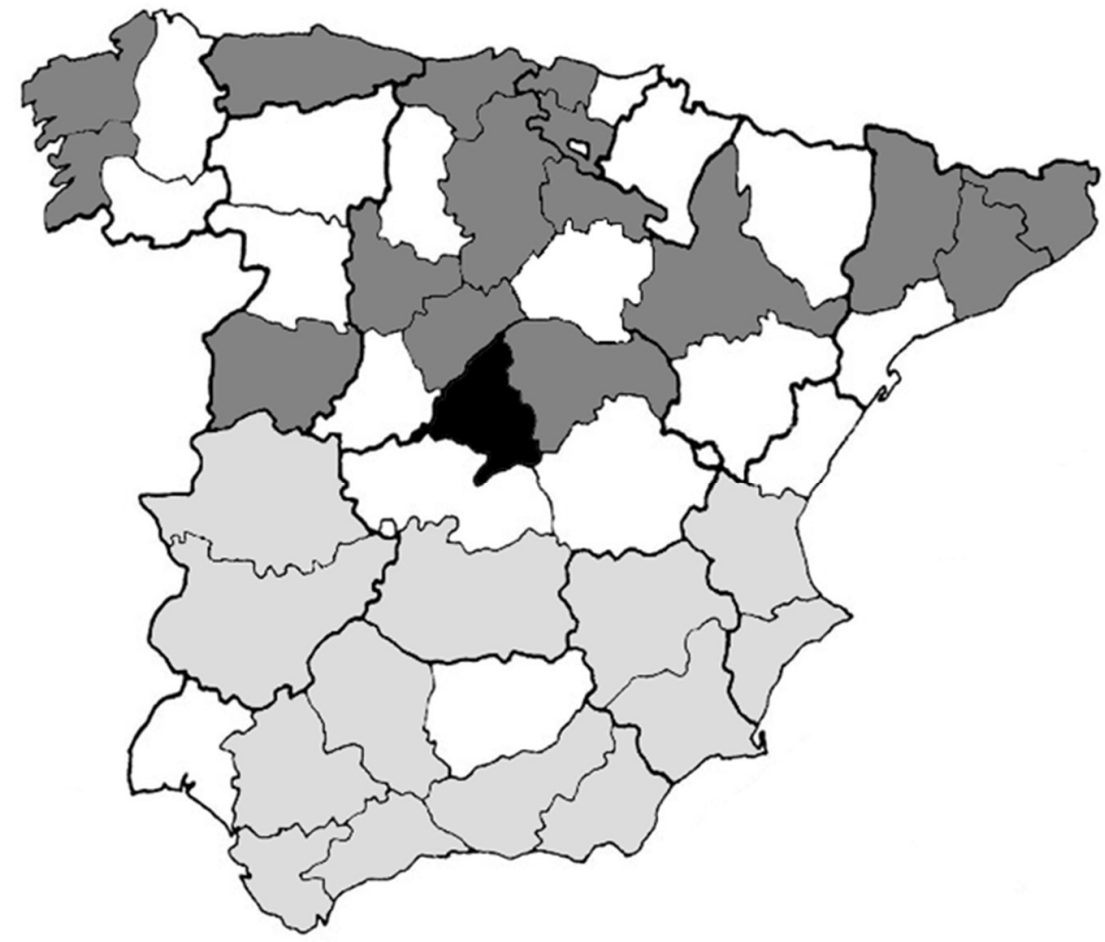


Figure S2. Distribution of acrylamide $\left(\mu g \mathrm{~kg}^{-1}\right)$ in fried potato, reducing sugars $\left(\mathrm{g} \mathrm{kg}^{-1}\right)$, and asparagine $\left(\mathrm{g} \mathrm{kg}^{-1}\right)$ in fresh potato, and polar compounds $\left(\mathrm{g}^{\left.100 \mathrm{~g}^{-1}\right)}\right.$ in frying oil.
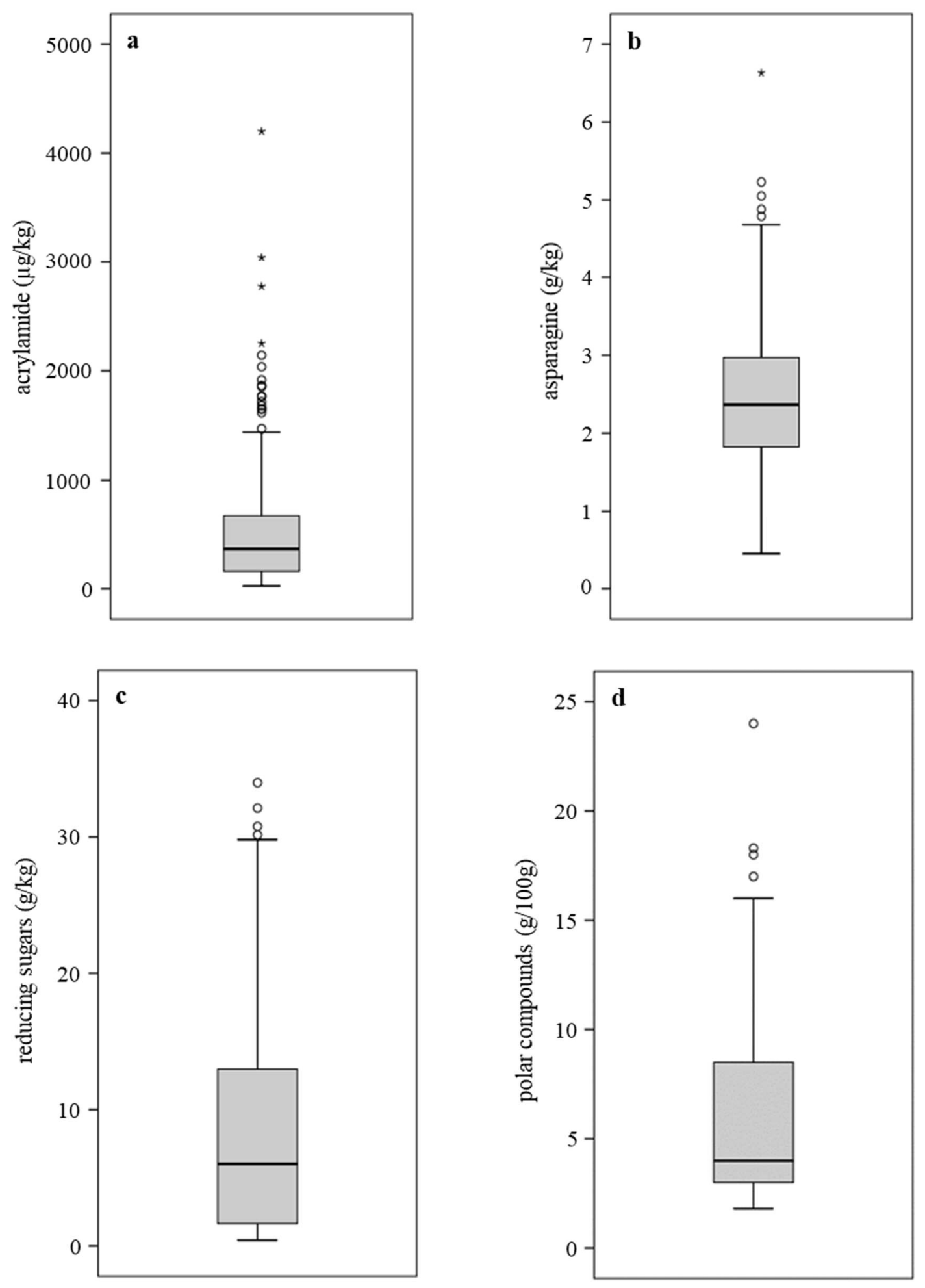
Figure S3. Box-plots of the colour parameter $a^{*}(a)$, and the moisture content in fresh tuber, fried potato, and weight loss (b).

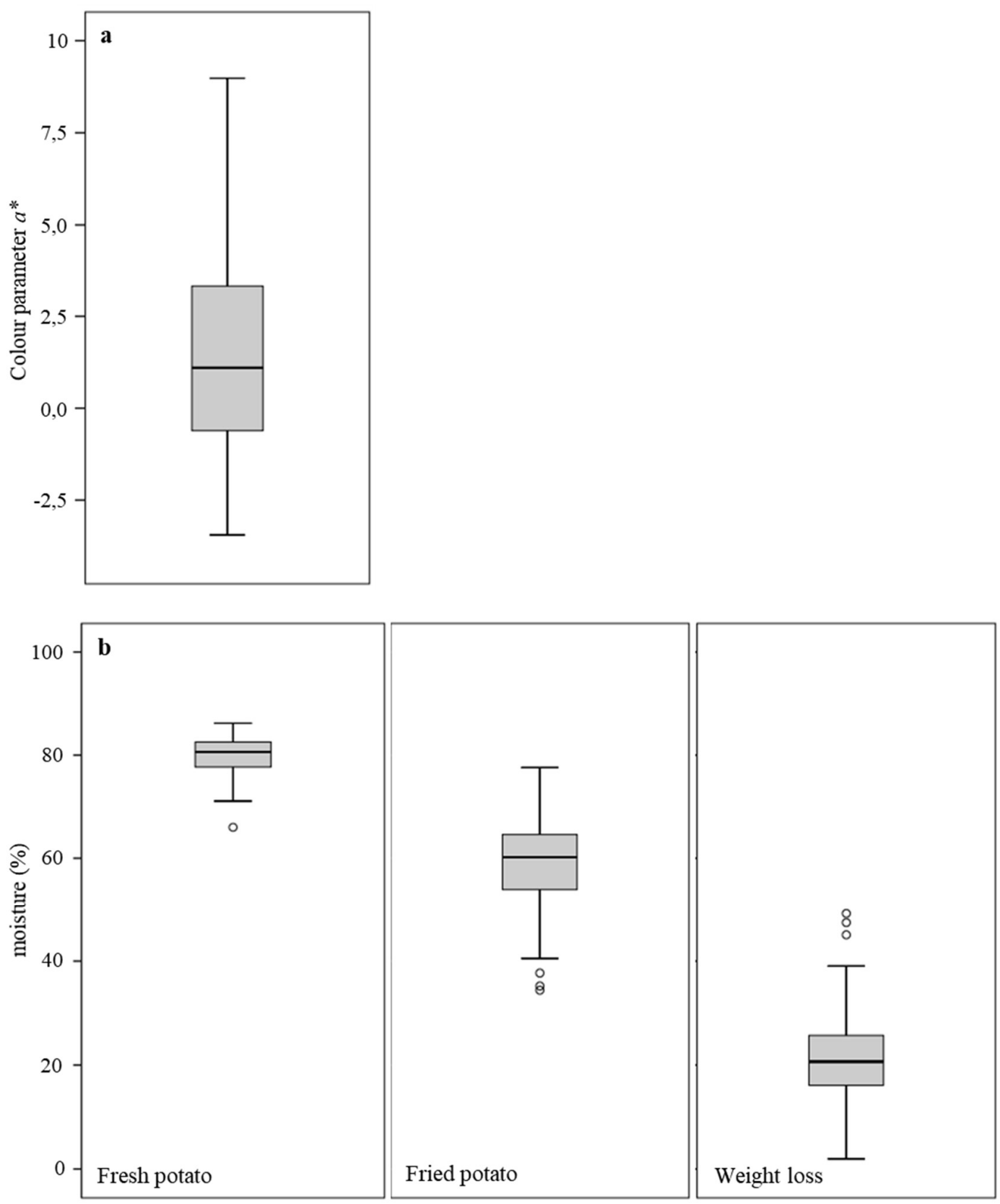


Table SI. One-way ANOVA and Student's t-test to stablish the effect of studied variables between groups on the acrylamide content (log 10 -back transformed). LL (lower) and UL (upper) limits at the $95 \%$ of confidence interval.

\begin{tabular}{|c|c|c|c|c|c|c|}
\hline Factor & mean & LL & UL & group & F-ratio & p-value \\
\hline Geographical & & & & & 1.780 & 0.1350 \\
\hline northwest & 257 & 27 & 2144 & $\mathrm{a}$ & & \\
\hline northeast & 358 & 48 & 1682 & $a b$ & & \\
\hline southwest & 375 & 55 & 3041 & $a b$ & & \\
\hline southeast & 392 & 46 & 4200 & $\mathrm{~b}$ & & \\
\hline centre & 419 & 73 & 1918 & $a b$ & & \\
\hline Consumption & & & & & 1.368 & 0.2540 \\
\hline weekly & 375 & 54 & 4200 & $\mathrm{a}$ & & \\
\hline monthly & 314 & 27 & 3041 & $\mathrm{a}$ & & \\
\hline exceptionally & 320 & 36 & 1918 & $\mathrm{a}$ & & \\
\hline Frying oil & & & & & 0.645 & 0.1783 \\
\hline sunflower & 345 & 46 & 2773 & $\mathrm{a}$ & & \\
\hline olive (virgin) & 318 & 27 & 1856 & $\mathrm{a}$ & & \\
\hline olive & 358 & 36 & 4200 & $\mathrm{a}$ & & \\
\hline blend & 484 & 299 & 831 & $\mathrm{a}$ & & \\
\hline Appliance & & & & & 0.540 & 0.5856 \\
\hline frying pan & 344 & 35 & 4200 & $\mathrm{a}$ & & \\
\hline fryer & 356 & 27 & 3041 & $\mathrm{a}$ & & \\
\hline other & 232 & 73 & 1042 & a & & \\
\hline Visual appearance & & & & & 63.75 & 0.0000 \\
\hline light-golden & 101 & 80 & 126 & a & & \\
\hline golden & 238 & 215 & 263 & $b$ & & \\
\hline dark-golden & 587 & 519 & 665 & c & & \\
\hline toasted & $|53|$ & 1195 & 1963 & d & & \\
\hline Factor & mean & $\mathbf{L L}$ & UL & group & $t$ & p-value \\
\hline City & & & & & 0.608 & 0.4370 \\
\hline$<50000$ & 2.5060 & 1.4314 & 3.4830 & $\mathrm{a}$ & & \\
\hline$>50000$ & 2.5556 & 1.5563 & 3.6232 & $\mathrm{a}$ & & \\
\hline
\end{tabular}

